\title{
A New Approach to the Prophylaxis of Cyclic Vomiting: Topiramate
}

\author{
Oya B Sezer ${ }^{1 *}$ and Taner Sezer ${ }^{2}$ \\ ${ }^{I}$ Department of Pediatric Gastroenterology and Nutrition, Kecioren Training and Research Hospital, Ankara, Turkey; and ${ }^{2}$ Department of \\ Pediatric Neurology, Baskent University Faculty of Medicine, Ankara, Turkey
}

\section{Background/Aims}

The aim of this study was to compare the efficacy and tolerability of topiramate and propranolol in preventing pediatric cyclic vomiting syndrome.

\section{Methods}

A retrospective medical-record review of patients who underwent prophylaxis after receiving a diagnosis of cyclic vomiting syndrome was performed. Patients who completed at least 12 months of treatment were included in the analysis. Responder rate, and adverseevent rates were also calculated from all patients. Response to treatment was assessed as the total number of vomiting attacks per year. Patients in whom the frequency of vomiting attack reduced greater or equal to $50 \%$ were defined as responders, and the remaining patients were classified as nonresponders.

\section{Results}

A total of 38 patients who were treated prophylactically with either topiramate (16 patients) or propranolol (22 patients) were identified. Fifty-nine percent of the patients in the propranolol group and $81 \%$ of the patients in the topiramate group reported freedom from attacks. A decrease of more than $50 \%$ in attacks per year occurred in $23 \%$ of patients in the propranolol group and $13 \%$ of patients in the topiramate group. The responder rates were $81 \%$ for propranolol group and $94 \%$ for topiramate group $(P=$ 0.001). Despite minor adverse effects (drowsiness, nervousness, and dizziness) observed in a few patients, the adverse event rates were not significantly different between the 2 groups $(P=0.240)$.

\section{Conclusions}

The efficacy of topiramate was superior to propranolol for the prophylaxis of pediatric cyclic vomiting syndrome.

(J Neurogastroenterol Motil 2016;22:656-660)

\section{Key Words}

Cyclic vomiting syndrome; Propranolol; Topiramate

\section{Introduction}

Cyclic vomiting syndrome (CVS) is a disease characterized

by recurrent episodes of incapacitating nausea and vomiting interspersed with relatively symptom-free intervals that might last anywhere from a few days to several months. ${ }^{1}$ Emesis is most intense and frequent within the first hour with a median frequency

Received: March 7, 2016 Revised: April 23, 2016 Accepted: April 27, 2016

(5) This is an Open Access article distributed under the terms of the Creative Commons Attribution Non-Commercial License (http://creativecommons. org/licenses/by-nc/4.0) which permits unrestricted non-commercial use, distribution, and reproduction in any medium, provided the original work is properly cited.

*Correspondence: Oya B Sezer, MD

Department of Pediatric Gastroenterology and Nutrition, Keçiören Training and Research Hospital, Ankara, Turkey Tel: +90-533-6915083, Fax: +90-312-3569002, E-mail: oyabalci@yahoo.com 
of 6 times/hour and it declines within 4-8 hours with the entire episode lasting on average between 2 and 3 days, although it may be longer (5-45 days). Other symptoms and signs commonly include abdominal pain in $80 \%$, headache or migraine in about $40 \%$, and nearly all children have pallor and fatigue. ${ }^{2}$ The prevalence of CVS in the pediatric population ranges from $0.3 \%$ to $15 \%$, depending on the study population and design. 3,4

CVS is generally believed to be a variant of migraine and the diagnosis is made by exclusion of other organic diseases. ${ }^{5}$ The possible etiologies have ranged from sympathetic and parasympathetic dysfunction, and stress/anxiety/depression. ${ }^{6}$ Treatment during the vomiting phase has the goals to prevent dehydration and to terminate the cycles of nausea, vomiting and abdominal pain. This involves rehydration, electrolyte and nutritional management, and antiemetic, antianxiety and/or analgesic medications. ${ }^{7}$ Prophylactic treatment is proposed to prevent recurrent episodes, abortive treatment and/or supportive care to ameliorate acute episodes. ${ }^{1,2,7}$ Preventive treatment with tricyclic antidepressants, $\beta$-adrenoceptor antagonists (propranolol) or cyproheptadine have been shown to be safe and effective in pediatric patients with $\mathrm{CVS}^{8-10}$ Also, drugs such as pizotifen, erythromycin, coenzyme Q10, and antiepileptics including valproate, phenobarbital, and topiramate can be used for CVS prophylaxis. ${ }^{11-15}$ Topiramate, an antiepileptic medication, has been used with increasing frequency in the treatment of nonepileptic periodic anomalies including headaches, abdominal migraine, and CVS. Few studies have been conducted to establish the efficacy of topiramate in childhood CVS. Ölmez et al ${ }^{16}$ reported a child with CVS whose symptoms resolved with topiramate. Boles ${ }^{12}$ reported 2 children with CVS, who were refractory to amitriptyline and cyproheptadine, and were succesfully treated with topiramate. Finally, in a last study, Kumar et $\mathrm{al}^{17}$ reported a response rate of $60 \%$ for topiramate in 30 patients with CVS. Propranolol is one of the most common and effective drug of choice for CVS. ${ }^{2,718}$ However, no study has compared topiramate with propranolol as a prophylactic treatment of pediatric CVS in real clinical practice settings. The purpose of this study was to perform a comparison of propranolol and topiramate in pediatric CVS.

\section{Materials and Methods}

Using our patient database, pediatric patients, aged $<18$ years, diagnosed with CVS and received a minimum of 12 months of therapy with either topiramate or propranolol were identified. Exclusion criteria were, the presence of gastrointestinal, neurological, or inherited metabolic diseases and the previous use of any drugs for the treatment of CVS including propranolol or topiramate. The diagnosis of CVS was established based on the International Headache Society 2004 Classification $^{19}$ and Rome III criteria. ${ }^{7}$ The baseline investigations performed on all CVS patients at the time of diagnosis in our departments included: complete blood count, liver function tests, creatinine, blood urea nitrogen, electrolytes, lipid profile, antinuclear antibody, lactate, pyruvate, ammonia, plasma amino acid, acylcarnitine profile, urine organic acid analysis, electroencephalogram, and abdominal ultrasonography. The starting dose of propranolol was $1 \mathrm{mg} / \mathrm{kg} / \mathrm{day}$, taken once and at night and the decision to increase the dose was also made after 1 month of treatment. The initial dose of topiramate was $25 \mathrm{mg}$ as a single nightly dose, and this dose was slowly increased to a maximum of $75 \mathrm{mg} /$ day until efficay was achieved.

Thirty-eight parents were sent a questionnaire asking questions pertaining to their perceived efficacy and tolerability of their child's experience with topiramate and propranolol. They were specifically asked to report the average number of attacks per year, duration of cycles (in hour), episodes of vomiting (per cycle), peak number of emesis (per hour) experienced, and also all adverse events during treatment.

Clinical follow-up information, regarding sex, age at diagnosis, duration and efficacy of treatment, and any adverse events were retrieved. Patients in whom the frequency of vomiting attacks were reduced by greater or equal to $50 \%$ were defined as responders, and the remaining patients were classified as nonresponders. Patients were considered as attack free if they did not have any attack for at least 1 year. The rate of adverse events and their profiles were also compared.

\section{Statistical Methods}

This study was approved by the Institutional Ethics Committee of our hospital (IRB number:2010/28B), and all patients' legal guardians gave informed consent prior to entering the study.

Statistical analysis was performed using SPSS 18.0 for Windows. To compare patient characteristics, Student's $t$ test was used for continuous variables. Fisher's exact test was used for the analysis of discrete variables based on sample size. A $P<0.05$ was considered significant.

\section{Results}

A total of 38 pediatric patients (16 males and 22 females) who were treated prophylactically with either topiramate or propranolol were identified. Topiramate was prescribed to 16 patients ( 5 males 
and 11 females) and propranolol was prescribed to 22 patients (10 males and 12 females). Subject age at the time of diagnosis ranged from 8 years to 14 years $(11.4 \pm 2.1$ years $)$ in the topiramate group and 9 years to 15 years $(12.6 \pm 1.8$ years $)$ in the propranolol group. The mean age at the time of treatment did not differ significantly between the 2 groups $(P=0.360)$ (Table).

The doses of topiramate among the responders ranged between
$25 \mathrm{mg}$ and $75 \mathrm{mg}$ per day. Of the responders, the final topiramate dose was $25 \mathrm{mg}$ in 14 patients, $50 \mathrm{mg}$ in 1 patient, and $75 \mathrm{mg}$ in 1 patient. The final maintenance dose of propranolol was $1.4 \mathrm{mg} /$ $\mathrm{kg} /$ day (5/22 patients). Treatment duration was shorter for the propranolol group $(16.8 \pm 2.2$ months vs $17.5 \pm 3.4$ months); however, this difference was not significant $(P=0.150)$.

The distribution and outcomes after the prophylactic treatment

Table. Demographic and Clinical Data of Subjects.

\begin{tabular}{|c|c|c|c|}
\hline Variables & $\begin{array}{l}\text { Propranolol } \\
(\mathrm{n}=22)\end{array}$ & $\begin{array}{c}\text { Topiramate } \\
(\mathrm{n}=16)\end{array}$ & $P$-value \\
\hline Age at diagnosis (yr) & $12.6 \pm 1.8$ & $11.4 \pm 2.1$ & 0.360 \\
\hline Sex (male/female) & $10 / 12$ & $5 / 11$ & 0.050 \\
\hline Treatment duration (mo) & $17.5 \pm 3.4$ & $16.8 \pm 2.2$ & 0.150 \\
\hline \multicolumn{4}{|l|}{ Parameters before treatment } \\
\hline Attack numbers per yr & $4.0 \pm 0.6$ & $5.0 \pm 0.1$ & 0.370 \\
\hline Median duration of cycles in $\mathrm{hr}$ & $19.0 \pm 4.3$ & $17.0 \pm 5.1$ & 0.060 \\
\hline Episodes of vomiting per cycle & $15.0 \pm 3.1$ & $14.0 \pm 2.3$ & 0.040 \\
\hline Peak number of emesis per $\mathrm{hr}$ & $6.0 \pm 0.1$ & $5.0 \pm 0.2$ & 0.050 \\
\hline \multicolumn{4}{|l|}{ Parameters after treatment period } \\
\hline Attack numbers per yr & $2.0 \pm 0.6$ & $1.0 \pm 0.4$ & 0.040 \\
\hline Median duration of cycles in $\mathrm{hr}$ & $15.0 \pm 1.4$ & $11.0 \pm 2.2$ & 0.001 \\
\hline Episodes of vomiting per cycle & $15.0 \pm 1.8$ & $12.0 \pm 1.4$ & 0.050 \\
\hline Peak number of emesis per $\mathrm{hr}$ & $5.0 \pm 0.1$ & $3.0 \pm 0.3$ & 0.040 \\
\hline \multicolumn{4}{|l|}{ Response to treatment } \\
\hline Attack free & $59 \%(13 / 22)$ & $81 \%(13 / 16)$ & 0.050 \\
\hline$\geq 50 \%$ decrease & $23 \%(5 / 22)$ & $13 \%(2 / 16)$ & 0.110 \\
\hline$<50 \%$ decrease or no change & $18 \%(4 / 22)$ & $6 \%(1 / 16)$ & 0.001 \\
\hline Adverse events (\%) & $14 \%(3 / 22)$ & $12 \%(2 / 16)$ & 0.240 \\
\hline Drowsiness & 1 & 1 & \\
\hline Nervousness & 1 & - & \\
\hline Dizziness & 1 & 1 & \\
\hline Mean weight change from baseline (kg) & $0.8 \pm 0.3(2.3 \%)$ & $-1.1 \pm 0.5(2.9 \%)$ & 0.320 \\
\hline
\end{tabular}

Data are expressed as mean $\pm \mathrm{SD}$.

$P<0.05$ is statistically significant.

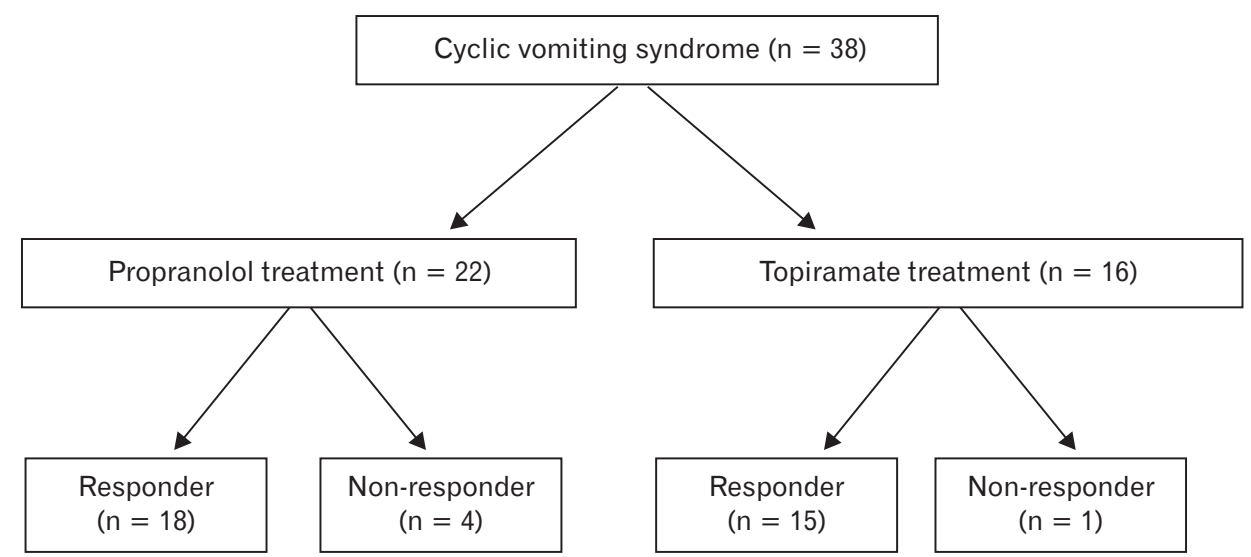

Figure. Diagram showing the distribution and outcomes after the prophylactic treatment for cyclic vomiting syndrome. 
for CVS are described in the Figure. After 12 months of treatment, $59 \%$ of the patients in the propranolol group and $81 \%$ of the patients in the topiramate group reported freedom from attacks. A decrease of more than $50 \%$ in attacks per year occurred in $23 \%$ of patients in the propranolol group and $13 \%$ of patients in the topiramate group. The responder rates were $82 \%$ for propranolol and $94 \%$ for topiramate $(P=0.001)$ (Table).

The average number of attacks per year, duration of cycles (in hour), episodes of vomiting (per cycle), and peak number of emesis (per hour) before and after the treatment period in either treatment group are described in the Table.

Four patients who were non-responsive to propranolol were treated with topiramate, and all of them had a satisfactory response. One patient who was non-responsive to topiramate was also nonresponsive to other medications as well including propranolol, amitriptyline and cyproheptadine.

The analysis revealed no statistically significant differences between the 2 groups for treatment related adverse effects $(P=0.150)$. In the topiramate group, 2 patients experienced mild adverse effects, which were drowsiness and dizziness. In the propranolol group, 3 patients experienced treatment related adverse effects that included drowsiness, nervousness, and dizziness. No dropouts occurred in our study due to adverse effects. Mean baseline body weight was $37 \pm 4.2 \mathrm{~kg}$ in the topiramate group and $35 \pm 2.1 \mathrm{~kg}$ in the propranolol group. In the topiramate group, the mean weight loss after the end of 12 months was $1.1 \pm 0.5 \mathrm{~kg}(2.9 \%)$. In the propranolol group, the mean weight gain after the end of 12 months was $0.8 \pm$ $0.3 \mathrm{~kg}(2.3 \%)$.

Finally, none of the study participants had a history of migraine or had any electroencephalographic abnormalities.

\section{Discussion}

Although several preventive agents have been demonstrated to be helpful, the treatment of CVS in children is difficult, and it takes several months to achieve effective relief. Tricyclic antidepressants like amitriptyline, antihypertensives like propranolol, and anticonvulsants such as valproate, phenobarbital and topiramate have been shown to be effective to prevent CVS in several studies. ${ }^{9-15}$ In our study, we compared the efficacy and safety of propranolol and topiramate in preventing pediatric CVS.

A $\beta$-adrenoceptor antagonist propranolol is recommended as a prophylactic drug in children with CVS of all ages. Aanpreung and Vajaradul ${ }^{20}$ compared amitriptyline, propranolol and pizotifen in pediatric CVS patients and they reported $61 \%, 50 \%$, and $50 \%$ response rates, respectively. In a study conducted on 14 pediatric CVS patients, a $67 \%$ response rate to propranolol was reported. ${ }^{9}$ In a last and retrospective study of 181 children with CVS, Haghighat et $\mathrm{al}^{15}$ reported that propranolol was significantly more effective than amitriptyline ( $92 \%$ vs $56 \%$ ) with a follow-up period ranging from 6 months to 12 years. In our study, $82 \%$ of the patients in the propranolol group responded to propranolol therapy.

Anticonvulsants, including phenobarbital, valproate, levetiracetam and topiramate, are also increasingly being used in the treatment of CVS. Topiramate has a number of physiologic effects that may play a role in CVS prevention, including blocking voltagedependent sodium channels, and augmenting the activity of the neurotransmitter gamma-aminobutyrate at some subtypes of the gamma-aminobutyric acid class A receptor. ${ }^{21}$ Among few studies investigating the effects of topiramate in CVS, Ölmez et $\mathrm{al}^{16} \mathrm{re}-$ ported a child having CVS with generalized epileptiform discharges who responded to topiramate therapy. In a last large single center study, Kumar et al. ${ }^{17}$ retrospectivly reviewed the clinical features of 101 pediatric-onset and adult-onset patients with CVS. In their study, the responder rate was reported to be $60 \%$ with topiramate. In our study, the response rate for topiramate was $94 \%$. Our results were inconsistent with the findings of Kumar et $\mathrm{al}^{17}$. A possible explanation for the higher responser rate might be associated with lower mean ages of our patients. To our knowledge, this is the first study to compare the efficacy of propranolol and topiramate for CVS prophylaxis in pediatric patients. The results of our study show that topiramate was superior to propranolol for the management of CVS.

The gender split is $23-58 \%$ male and $42-86 \%$ female in pediatric CVS patients. ${ }^{1-4}$ In our study, male patients were more frequent in the propranolol group. The effect of sex difference on response to treatment has not been investigated in previously published studies. Therefore, male predominance in the propranolol group might not affect the treatment outcomes in our study.

The most frequently reported adverse effects related to propranolol or topiramate included restlessness, sleep disturbance, asthenia, dizziness, somnolence, ataxia, tremors, dysarthria, blurred vision, gastrointestinal symptoms, and weight loss. ${ }^{16,17,22}$ In the present study, the most commonly observed side effects in both groups included drowsiness, nervousness and dizziness. Weight loss due to appetite decrease is a frequent side effect of topiramate. In our study, we observed only mild weight loss (2.9\% of initial body weight) on topiramate.

As the side effects can be minimized by increasing the dose slowly, topiramate was administered at the lowest dose effective. In 
our study, the responder criteria at $25 \mathrm{mg} /$ day was achieved by all the responders, except two, in the topiramate group.

One of the most important limitation is the retrospective nature of the study. Although the 12-months treatment period was shorter and the size of the sample was smaller than many studies on CVS, we found that topiramate appeared to be more effective than propranolol in the prophylaxis of CVS.

In conclusion, the efficacy of topiramate was superior to that of propranolol for pediatric CVS. Adverse effect rates did not differ between the treatment groups. Further open- label and controlled trials with larger sample sizes, longer treatment periods and additional test drugs should be conducted on investigating optimal treatment in pediatric CVS.

\section{Financial support: None.}

\section{Conflicts of interest: None.}

Author contributions: Oya B Sezer: substantial contributions to the conception and design, the acquisition, analysis, or interpretation of the data; Taner Sezer: final approval of the version to be published; and all authors: drafting of the article or critical revision for important intellectual content.

\section{References}

1. Abell TL, Adams KA, Boles RG, et al. Cyclic vomiting syndrome in adults. Neurogastroenterol Motil 2008;20:269-284.

2. Yang HR. Recent concepts on cyclic vomiting syndrome in children. J Neurogastroenterol Motil 2010;16:139-147.

3. Ertekin V, Selimoglu MA, Altnkaynak S. Prevalence of cyclic vomiting syndrome in a sample of Turkish school children in an urban area. J Clin Gastroenterol 2006;40:896-898.

4. Fitzpatrick E, Bourke B, Drumm B, Rowland M. The incidence of cyclic vomiting syndrome in children: population-based study. Am J Gastroenterol 2008;103:991-995.

5. Drossman DA. The functional gastrointestinal disorders and the Rome III process. Gastroenterology 2006;130:1377-1390.

6. Hejazi RA, Lavenbarg TH, Pasnoor M, et al. Autonomic nerve function in adult patients with cyclic vomiting syndrome. Neurogastroenterol Motil 2011;23:439-443.
7. Li BU, Lefevre F, Chelimsky GG, et al. North American Society for Pediatric Gastroenterology, Hepatology, and Nutrition consensus statement on the diagnosis and management of cyclic vomiting syndrome. J Pediatr Gastroenterol Nutr 2008;47:379-393.

8. Forbes D, Withers G. Prophylactic therapy in cyclic vomiting syndrome. J Pediatr Gastroenterol Nutr 1995;21(suppl1):S57-S59.

9. Andersen JM, Sugerman KS, Lockhart JR, Weinberg WA. Effective prophylactic therapy for cyclic vomiting syndrome in children using amitriptyline or cyproheptadine. Pediatrics 1997;100:977-981.

10. Ghosh JB, Roy M, Peters T. Cyclic vomiting syndrome responding to amitryptiline. Indian J Pediatr 2009;76:1261-1262.

11. Vanderhoof JA, Young R, Kaufman SS, et al. Treatment of cyclic vomiting in childhood with erythromycin. J Pediatr Gastroenterol Nutr 1995;21(suppl1):S60-S62.

12. Boles RG. High degree of efficacy in the treatment of cyclic vomiting syndrome with combined co-enzyme Q10, L-carnitine and amitriptyline, a case series. BMC Neurol 2011;11;102.

13. Gokhale R, Huttenlocher PR, Brady L, Kirschner BS. Use of barbiturates in the treatment of cyclic vomiting during childhood. J Pediatr Gastroenterol Nutr 1997;25:64-67.

14. Hikita T, Kodama H, Nakamoto N, et al. Effective prophylactic therapy for cyclic vomiting syndrome in children using valproate. Brain Dev 2009;31:411-413.

15. Haghighat M, Rafie SM, Dehghani SM, Fallahi GH, Nejabat M. Cyclic vomiting syndrome in children: experience with 181 cases from southern Iran. World J Gastroenterol 2007;13:1833-1836.

16. Olmez A, Köse G, Turanli G. Cyclic vomiting with generalized epileptiform discharges responsive to topiramate therapy. Pediatr Neurol 2006;35:348-351.

17. Kumar N, Bashar Q, Reddy N, et al. Cyclic vomiting syndrome (CVS): is there a difference based on onset of symptoms--pediatric versus adult? BMC Gastroenterol 2012;12:52.

18. Yang HR, Ko JS, Seo JK. A Study on the disease course and prognosis of cyclic vomiting syndrome. J Korean Pediatr Soc 2001;44:1141-1156.

19. Headache Classification Subcommittee of the International Headache Society. The international classification of headache disorders, 2 nd ed. Cephalalgia 2004;24(suppl 1):S1-S160.

20. Aanpreung P, Vajaradul C. Cyclic vomiting syndrome in Thai children. J Med Assoc Thai 2002;85(suppl 2):S743-S748.

21. Greenfield LJ Jr. Molecular mechanisms of antiseizure drug activity at $\mathrm{GABA}_{\mathrm{A}}$ receptors. Seizure 2013;22:589-600.

22. Garg KC, Singhal KC, Kumar S, Lal A. Adverse reactions to propranolol, a non-selective beta-adrenergic blocking agent in hypertensive patients-a collaborative study. Indian J Physiol Pharmacol 1993;37:67-70. 